\title{
Supercritical water oxidation for energy production by hydrothermal flame as internal heat source. Experimental results and energetic study
}

\author{
Pablo Cabeza, Joao Paulo Silva Queiroz ${ }^{1,}$, Manuel Criado, Cristina Jimenez, \\ Maria Dolores Bermejo*, Fidel Mato, Maria Jose Cocero \\ High Pressure Process Group, Dept. of Chemical Engineering and Environmental \\ Technology - Universidad de Valladolid - Doctor Mergelina, s/n, 47011, Valladolid - Spain
}

\begin{abstract}
This work presents experimental and model results from a new configuration of a cooled wall reactor working with two outlets: an upper outlet through which a salt-free hot effluent $\left(500-600{ }^{\circ} \mathrm{C}\right)$ is obtained and a lower outlet through which an effluent at subcritical temperature dissolving the precipitated salts is obtained. Different flow distributions were tested in order to find the best elimination conditions. Total organic carbon removal over $99.99 \%$ was obtained at injection temperatures as low as room temperature, when the fraction of products leaving the reactor in the upper effluent is lower than $70 \%$ of the feed flow. The performance of the reactor was tested with the oxidation of a recalcitrant compound such as ammonia, using isopropyl alcohol as co-fuel. Removals higher than $99 \%$ of $\mathrm{N}_{-} \mathrm{NH}_{4}^{+}$were achieved in both effluents, working with temperatures near $700{ }^{\circ} \mathrm{C}$. Slightly better eliminations were obtained in the bottom effluent because its residence time in the reactor is longer. The behavior of the reactor working with feeds with a high concentration of salts was also tested. Feeds containing up to $2.5 \%$ wt $\mathrm{Na}_{2} \mathrm{SO}_{4}$ could be injected
\end{abstract}

\footnotetext{
*Corresponding author. Phone: +34 983423166

Email addresses: palabreras@gmail.com (Pablo Cabeza), joao.deq@gmail.com (Joao Paulo Silva Queiroz), mcriado_sastre@hotmail.com (Manuel Criado), crisbaterna@gmail.com (Cristina Jimenez), mdbermejo@iq.uva.es (Maria Dolores Bermejo), fidel@iq.uva.es (Fidel Mato), mjcocero@iq.uva.es (Maria Jose Cocero)

${ }^{1}$ Present address: Dept. of Chemical Engineering - Universidade Federal de Pernambuco Prof. Artur de Sá, s/n, - Cidade Universitária - 50740-521, Recife, PE - Brazil
} 
in the reactor without plugging problems and a total organic carbon removal of $99.7 \%$ was achieved in these conditions. Upper effluent always presented a concentration of salt lower than $30 \mathrm{ppm}$. Finally, a theoretical analysis of the energy recovery of the reactor working with two outlets was made.

Keywords: Supercritical water oxidation, Hydrothermal flames, Renewable Energy, Reactor design

\section{Introduction}

Since Franck and coworkers discovered hydrothermal flames [1] and it could be applied to the Supercritical Water Oxidation (SCWO), new challenges came 4 up to the study of SCWO. For flammable compounds such as methane or 5 methanol, hydrothermal flame can occur at temperatures as low as $400{ }^{\circ} \mathrm{C}[2]$. 6 SCWO is the oxidation of organics in water under conditions above its critical 7 point. In presence of hydrothermal flames the reaction times can be reduced to 8 the order of milliseconds [3] without the production of sub-products typical of 9 conventional combustion such as NOx [4] or dioxins [5].

SCWO with a hydrothermal flame has a number of advantages over the 11 flameless process. Some of these advantages permit overcoming the traditional 12 challenges that make the successful and profitable commercialization of SCWO

13 technology difficult. The advantages include the following [3]:

- The reduced residence times (in the order of milliseconds) allows the construction of smaller reactors.

- It is possible to carry out the reaction with feed injection temperatures near to room temperature when using vessel reactors $[6,7]$. This avoids problems such as plugging and corrosion in a preheating system, having an advantage from the operational and energy integration perspective.

- Higher operation temperatures improve the energy recovery.

The first reactor probably working with a hydrothermal flame inside was the MODAR reactor, working in conditions of concentration, temperature and 
pressure above the ignition conditions of methanol and being able to work with injection temperatures of $25{ }^{\circ} \mathrm{C}$ and injecting the air at $220{ }^{\circ} \mathrm{C}$ [7]. In the ETH of Zurich, the direct injection of the waste into a diffusion hydrothermal flame generated inside the reactor was developed as a solution to avoid the external preheating of the waste up to supercritical conditions [8, 9]. Príkopský and coworkers investigated the feasibility of injecting feeds with a $3 \%$ wt of sodium sulfate $\left(\mathrm{Na}_{2} \mathrm{SO}_{4}\right)$ in the transpiring wall reactor (TWR) with a diffusion hydrothermal flame as internal heat source [10]. No plugging was observed during the experiments, but salt deposits were detected in the upper hot zone of the reactor. In a previous investigation of our research group [6], it was found that using a transpiring wall reactor, a premixed hydrothermal flame inside the reaction chamber could be maintained when injecting the feed at a temperature as low as $110^{\circ} \mathrm{C}$. Using a similar reactor, feeds with up to $4.74 \% \mathrm{wt}$ $\mathrm{Na}_{2} \mathrm{SO}_{4}$ could be injected [11]. The reactor worked without plugging, but the recovery of salts was only between $5 \%$ and $50 \%$. Both research groups reported an increase in the temperature when salt was injected in the reactor $[10,11]$. Zhang et al. [12] studied the operational parameters of a TWR developed to generate thermal fluids for oil recovery. They used water-methanol as artificial fuel prior to treating oil exploration wastewater, and they found the limits of temperature of transpiring flow in order to avoid the quenching and extinction of hydrothermal flame.

It has been proved that injection of cold feeds over a hydrothermal flame is only possible when working with vessel reactors $[9,10,11]$ and it is not possible when working with tubular reactors [13]. This behavior was due to the low flame front velocities in hydrothermal flames that is lower than $0.1 \mathrm{~m} / \mathrm{s}$, in comparison to the higher flame front velocities at atmospheric conditions (0.4-3 $\mathrm{m} / \mathrm{s}$ ). This is the reason why flow velocities lower than $0.1 \mathrm{~m} / \mathrm{s}$ are necessary to keep a stable hydrothermal flame where cold reagents can be injected [14]. Our research group has succeeded in keep working continuously a vessel reactor injecting feeds at temperatures as low as $25^{\circ} \mathrm{C}[15]$.

Even though the most immediate application of hydrothermal flames is in 
the SCWO process for waste destruction, which is the most industrially developed hydrothermal process, it is possible to move from the idea of hydrothermal flame as a technology for the destruction of wastes to consider it as a technology for the generation of clean energy, which could eventually substitute the actual technologies based on atmospheric combustion [16]. Supercritical water is already applied in energy fields through gasification processes for waste valorization Facchinetti et al. [17], Rönnlund et al. [18]. The efficiency in energy production by SCWO of coal and direct expansion of the effluent was compared to the efficiency of other conventional power plants by Bermejo et al. [19]. If the steam was produced at $650{ }^{\circ} \mathrm{C}$ and $30 \mathrm{MPa}$, efficiencies as high as $38 \%$ were obtained by SCWO. Efficiency was as high as $41 \%$ if the effluent was reheated and expanded a second time. The efficiencies at the same steam conditions for pulverized coal power plant and pressurized fluidized bed power plant were 32 and $34 \%$ respectively. Comparison is more favorable using oxygen enriched air or even using pure oxygen as the oxidant. In this last option the cost of the oxidant must be assumed. Nevertheless, it is known that in traditional combustion power plants, oxygen is used to improve efficiency. Donatini et al. [20] simulated a power plant based on direct combustion of pulverized coal in a SCWO reactor with a system for $\mathrm{CO}_{2}$ capture. They reported net efficiencies around $27 \%$ and found that the consumption of the air separation unit for oxygen production strongly affects the viability of the plant. A similar analysis has been made by Kotowicz and Michalski [21], whom have proposed several operations in order to increase efficiency for each step in a power plant model: air separation unit, boiler (SCWO reactor burning coal) and steam turbine.

Arai et al. [22] proposed the supercritical oxidation of biomass wastes and other sustainable fuels with a hydrothermal flame as a clean energy source for reaching a sustainable society with a decentralized production based on renewable resources. Augustine and Tester [3] also propose its utilization with low grade fuels. In general, this technology can be applied to the valorization of waste such as waste water treatment plant sludge, biomass or plastic wastes or any kind of waste with high energetic content. Basic theoretical calculations 
indicate that feeds with an energy content of $930 \mathrm{~kJ} / \mathrm{kg}$ (roughly equivalent to an aqueous solution with $2 \%$ ww of hexane) can supply enough energy to preheat the feed from room temperature up to $400{ }^{\circ} \mathrm{C}$, and to generate electric power equivalent to that consumed by the high pressure pump and the air compressor [23]. A remarkable aspect about working with hydrothermal flames is improving energy recovery in SCWO system [19]. Hydrothermal flames allow new reactor designs that not only are able to inject feeds without preheating because of the possibility of injecting reactants at room temperature but also use the heat released by the flame for other purposes as the energetic integration of the process or for production of electricity by turbines [24]. Smith Jr. et al. [25] used exergy analysis to study the partial and total oxidation of methane in supercritical water for a heat-integrated supercritical water reactor and electrical energy production system. They assume a direct expansion of products (at $400{ }^{\circ} \mathrm{C}$ ) in a turbine, followed by heat recovery of the expanded stream. It was found that the process could be energy self-sufficient and optimum flow rates were calculated in order to minimize reactor heat requirements or maximize net electrical work. The high temperature effluent can also be used as heat source in other hydrothermal processes, such as liquefaction or gasification, where the heat recovery is a critical issue $[26,27]$. In the case of waste with high concentration of inorganic substances, new reactor designs able to separate these salts from the effluent must be developed in order to make it possible to directly expand the effluent in an electricity production turbine.

The main goal of this work is the study of the behavior of new cooled wall reactor with the main particularity of having two outlets in order to try to keep the maximum heat released by the flame in a clean and high temperature flow leaving the reactor from the upper zone and other flow at subcritical conditions with the salts dissolved going out for the bottom of the reactor. In this way the upper/lower effluent relation was optimized taking into account the temperature profiles inside the reactor and the organic matter elimination in both streams. The performance of the reactor with recalcitrant pollutants such as ammonia was tested as well as the performance of the reactor with feeds containing salts. 


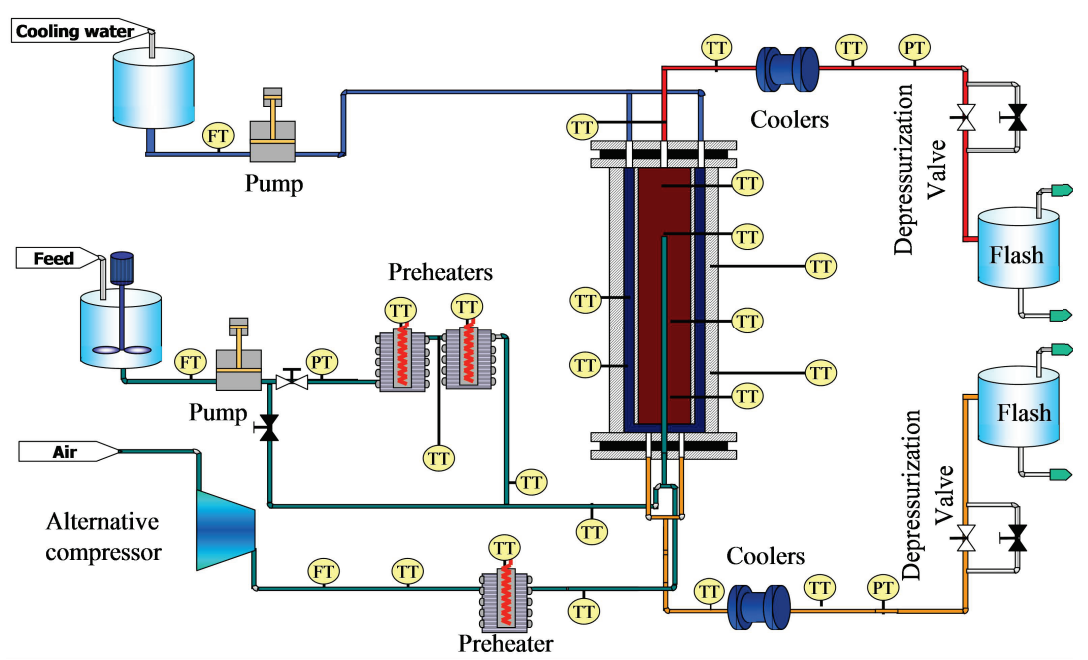

Figure 1: Diagram of SCWO facility with two outlets.

A CFD model is also used to describe the behaviour of the reactor. Finally, a purely theoretical energy recovery study of the process with the new reactor was performed, including the possibility of direct expansion in hypothetical devices.

\section{Experimental}

\subsection{Experimental setup}

All the experiments analyzed in this research have been carried out in the SCWO facility installed in the University of Valladolid. It consists of a continuous facility working with a feed flow of $22.5 \mathrm{~L} / \mathrm{h}$, and air supplied by a four stage compressor, with a maximum feed rate of $36 \mathrm{~kg} / \mathrm{h}$ is used as the oxidant. The reactor consist of a pressure vessel made of AISI 316 stainless steel able to stand a maximum pressure of $30 \mathrm{MPa}$ and a maximum wall temperature of 400

${ }^{\circ} \mathrm{C}$, containing a reaction chamber made of Ni-alloy 625 where the temperature be as high as $700{ }^{\circ} \mathrm{C}$. Waste water feed and air are previously pressurized and preheated with electrical resistances to the desired temperature before being injected by the bottom of the reactor. The reagents are conducted to the top of

the reactor chamber by means of a tubular injector. At the outlet of the injec- 
tor the hydrothermal flame is formed. Cooling water, previously pressurized is circulating between the pressure vessel and the reaction chamber introduced by the top of the reactor in order to cool down the vessel at a temperature lower

than $400{ }^{\circ} \mathrm{C}$. This cooling water is entering in the reaction chamber through its lower part and leaving the reactor by the bottom together with a fraction of the products. The rest of the products leave the reactor by another outlet situated in the top of the reactor chamber. After leaving the reactor, both effluents are cooled down in the intercoolers and depressurized. The flow diagram of the facility with two outlets is shown in Figure 1. More information about the facility can be found elsewhere $[6,13]$. Figure 2 shows a scheme of the reactor with the different position of thermocouples inside the reaction chamber. The different temperature profiles are referred at the position of these four thermocouples. Each effluent (top and bottom flow) is measured with a rotameter in order to know the distribution of the feed flow respect the two outlets.

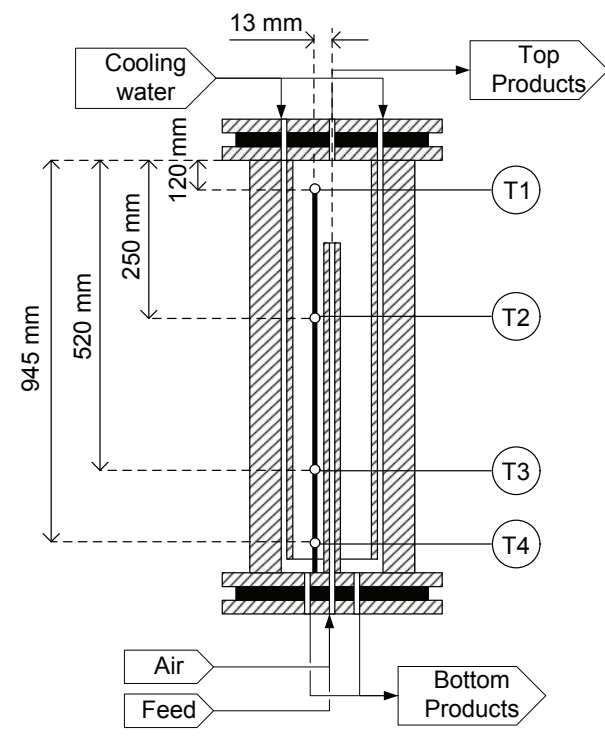

Figure 2: Scheme of the reactor with the flow distribution and the positions ( $\mathrm{mm}$ ) of the temperature measurement inside the reaction chamber. 


\subsection{Materials and experimental procedure}

The experiments analyzed in this research were performed using feeds prepared with isopropyl alcohol (IPA, 99\% purity) and tap water without further purification. For experiments made with ammonia it was used ammonia $(25 \%$ in mass). Synthetic waste containing salts were prepared using $\mathrm{Na}_{2} \mathrm{SO}_{4}$ (purity $>98 \%)$.

Previous to the beginning of the experiment the reactor must be preheated electrically to $400{ }^{\circ} \mathrm{C}$. The reaction is initiated by injected air and waste water streams preheated electrically up to a temperature higher than $400{ }^{\circ} \mathrm{C}$. A few minutes after continuous injecting of IPA solution and air stream the hydrothermal flame is ignited. At that moment a sharp increase the temperatures at the top of the reactor (T1 and T2) is registered. Then, the electrical heating of the wall of the reactor is turned off and the cooling water flow is connected. For keeping the maximum temperature constant in values around $600-700{ }^{\circ} \mathrm{C}$ till the desired injection temperature is reached, IPA concentration was increased as the injection temperature was decreased down to the selected injection temperature. After the target injection temperature is reached (from $300{ }^{\circ} \mathrm{C}$ till room temperature, around $20-30{ }^{\circ} \mathrm{C}$ ), the upper flow and bottom flow are regulated opening or closing the decompression valves keeping the air and the pressure constant. Pressure must be stabilized around $23 \mathrm{MPa}$. Several stationary states with different prepared feeds and different flow up/bottom ratio are reached and samples of the liquid effluent are taken.

Total Organic Carbon (TOC) and Total Nitrogen (TN) analysis of the samples were performed with a TOC 5050 SHIMADZU Total Organic Carbon Analyzer which uses combustion and IR analysis. The detection limit is $1 \mathrm{ppm}$. Salt concentration is measured using a conductimeter Basic 30 provided by Crison. For doing this, conductivities of solutions of known $\mathrm{Na}_{2} \mathrm{SO}_{4}$ concentration are measured obtaining a linear calibration line between conductivity and $\mathrm{Na}_{2} \mathrm{SO}_{4}$ concentration. Nitrates and nitrites were characterized in the liquid effluent by ionic chromatography with an IC PAK A column of Waters. The detection limit is 1 ppm. $\mathrm{NH}_{3}$ and $\mathrm{NO}_{x}$ at the gas effluent were analyzed with Dräger tubes 
detectors Lab Safety Supply CH29401 and CH31001. The $\mathrm{NO}_{x}$ detection limits for these tubes ranged from 0.5 to $100 \mathrm{ppm}$ and the $\mathrm{NH}_{3}$ detection limits ranged from 5 to 70 ppm (standard deviation for both tubes are between 10 and 15\%).

\section{Modeling}

A CFD model was performed in order to study the internal behavior of the new reactor. The main elements of the reactor have been included in the model geometry, like the injector, the reaction chamber, and the space between the pressure shell and the chamber. The reactor is modeled as an axisymmetric $2 \mathrm{D}$ system. The turbulent flow dynamics is modeled by Reynolds-Averaged-NavierStokes equations, using the Realizable k- $\epsilon$ turbulence model with enhanced wall treatment [28]. The density of the supercritical mixture is calculated by PengRobinson equation of state with Van der Waals mixing rules, and volume translation (VTPR-EoS) [29]. The volume translation used in density calculations was fitted for each component that constitutes the system $\left(\mathrm{H}_{2} \mathrm{O}, \mathrm{O}_{2}, \mathrm{~N}_{2}, \mathrm{CO}_{2}\right.$ and IPA), at the operation pressure of $23 \mathrm{MPa}$. The volume translation has not influence on enthalpy calculations, thus, specific enthalpy (and also cp) is given by original Peng-Robinson equation of state (PR-EoS) [30]. The thermal conductivity and the molecular viscosity of the mixture are calculated as a mass-fraction average of the properties of the pure components as function of temperature. The turbulent diffusion usually overwhelms laminar diffusion, and the specification of detailed laminar diffusion properties in turbulent flows is not necessary. Even so, laminar diffusion coefficient are estimated using the method of Mathur and Thodos [31].

\section{Results and discussion}

As general result, the new reactor with two outlets successfully eliminates organic material and provides a clean stream with high energy content. The injection at low temperatures $\left(20^{\circ} \mathrm{C}\right)$, far from the critical region, keeps the salts dissolved inside the injector, avoiding plugging and corrosion. Finally, 
the cooling water entering the reaction chamber at the bottom forms a pool at subcritical temperature capable of redissolving salts (if they are present) before leaving the reactor.

\subsection{Description of parameters}

The performance of the reactor is studied by a set of parameters described in this section. The fraction of flow leaving the reactor by the top outlet is defined as the ratio of the upper effluent liquid flow, measured after decompression, to the feed flow, as shown in eq. (1).

$$
\text { Upper effluent fraction }(\%)=\frac{F_{\text {top,liq }}}{F_{\text {feed,liq }}} \cdot 100
$$

As the cooling water mixes the flow that comes out the reactor at the bottom outlet, the samples taken at the bottom flow must be corrected in order to know the real concentration of TOC and TN at the bottom effluent. The concentration of top effluent does not have to be corrected since this flow is not mixed with the cooling water flow:

$$
\begin{gathered}
T O C_{\text {bottom }}=T O C_{\text {bottom measured }} \frac{F_{\text {feed }}+F_{\text {cooling }}-F_{\text {top }}}{F_{\text {feed }}-F_{\text {top }}} \\
T N_{\text {bottom }}=T N_{\text {bottom measured }} \frac{F_{\text {feed }}+F_{\text {cooling }}-F_{\text {top }}}{F_{\text {feed }}-F_{\text {top }}}
\end{gathered}
$$

For simplicity of notation, in equations (2), (3) and the sequence of the document, $F_{\text {feed }}$ considers only the liquid flow feed. Once the TOC and TN are corrected, it can be calculated the removal efficiency for each effluent:

$$
\begin{gathered}
T O C \text { removal }_{\text {top } / \text { bottom }}=\left(1-\frac{T O C_{\text {top } / \text { bottom }}}{T O C_{\text {feed }}}\right) \cdot 100 \\
N-N H_{4}^{+} \text {removal }_{\text {top } / \text { bottom }}=\left(1-\frac{N-N H_{4 \text { top } / \text { bottom }}^{+}}{N-N H_{4 \text { feed }}^{+}}\right) \cdot 100
\end{gathered}
$$

$\mathrm{N}_{-} \mathrm{NH}_{4}^{+}$concentration in the effluent is obtained from the difference of TN and the concentration of nitric Nitrogen $\left(\mathrm{N}-\mathrm{NO}_{3}\right.$ and $\left.\mathrm{N}-\mathrm{NO}_{2}\right)$. The fraction of $\mathrm{Na}_{2} \mathrm{SO}_{4}$ recovered in the effluents is defined in eq. (6).

Salt recovery top $/$ bottom flow $=\frac{C_{N a_{2} S O_{4}, \text { top } / \text { bottom }} \cdot F_{\text {top } / \text { bottom }}}{C_{N a_{2} S O_{4}, \text { feed }} \cdot F_{\text {feed }}} \cdot 100$ 


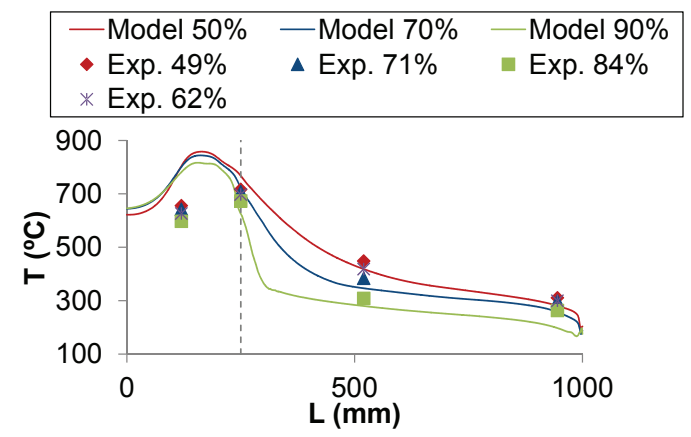

Figure 3: Temperature profiles for different upper effluent fractions at $20{ }^{\circ} \mathrm{C}$. Symbols stand for experimental data, while continuous lines come from CFD model. The vertical dashed line indicates the position of the outlet of the injector.

219

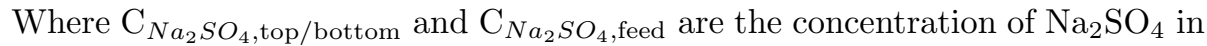
$\%$ wt in the top/bottom effluent and in the feed respectively.

4.2. Influence of the upper effluent fraction.

4.2.1. Temperature profiles inside the reactor.

With the new configuration of the reactor, the first point was the study of the influence of upper flow fraction (eq. (1)) in order to check how the new outlet affects the behavior of the hydrothermal flame. Experiments were made with injections at room temperature and at $200{ }^{\circ} \mathrm{C}$. In order to analyze the results, the experimental temperature profiles registered along the reactor for the different flow distributions were compared in figure 3, which shows experimental and model results for temperature at different lengths of the reactor. It can be

indicates the position of the outlet of the injector.

observed that when the upper flow increases, all the temperatures inside the reactor decrease. This is because the top outlet is closer to the injector outlet and when a higher fraction is leaving the reactor by the top a low amount of products in flowing down the reactor. Thus, the heat content of this flow fraction is not transmitted to the reaction chamber and to the reagents entering through the injector. 


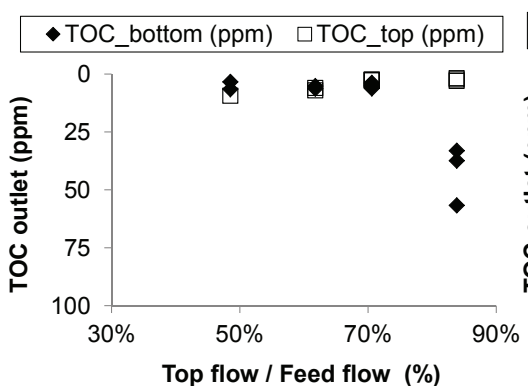

(a)

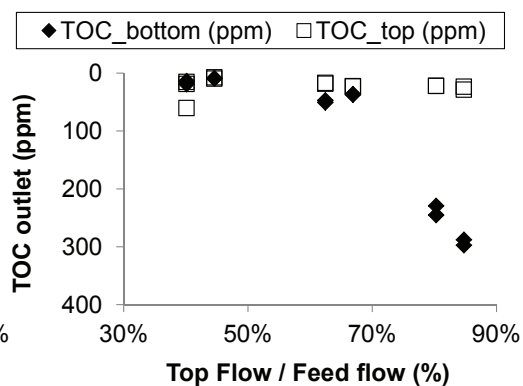

(b)

Figure 4: Values of TOC in the top and bottom effluent as a function of the upper effluent fraction at injection temperature of (a) $20{ }^{\circ} \mathrm{C}$ and $13.5 \%$ of IPA, (b) $200{ }^{\circ} \mathrm{C}$ and $10.5 \%$ of IPA.

In the figure 4 the TOC concentration in both effluents was plotted as a function of the upper flow fraction. In figure $4 \mathrm{a}$ the feed inlet temperature is $20{ }^{\circ} \mathrm{C}$ (room T) and in figure $4 \mathrm{~b}$ the feed inlet temperature is $200{ }^{\circ} \mathrm{C}$. In both

experiments TOC removals higher than $99.99 \%$ were obtained in both effluents when the fraction of effluent leaving the reactor by its upper part is below $70 \%$.

Thus, the optimum upper effluent fraction, among those tested, is around this value. This behavior could be explained because the increasing the upper flow fraction can elongate the flame and make that some bottom products do not react completely because they do not pass through the flame.

\subsection{Model results}

Figure 5 shows the temperature field (and the pathlines) predicted by the CFD model and validated with experimental data in section 4.2. It corresponds to an experiment with $13 \mathrm{~kg} / \mathrm{h}$ of feed (13.5\% IPA) and stoichiometric air at 20 ${ }^{\circ} \mathrm{C}$, where the upper effluent fraction is $70 \%$ (see eq. (1)). It can be observed from the pathlines that part of the reactor content flows directly to the top outlet, while another fraction goes trough a recycling zone before leaving the reactor at the bottom. The model correctly reproduces experimental temperature profiles (figure 3), and allows to predict the composition of the outlets. 


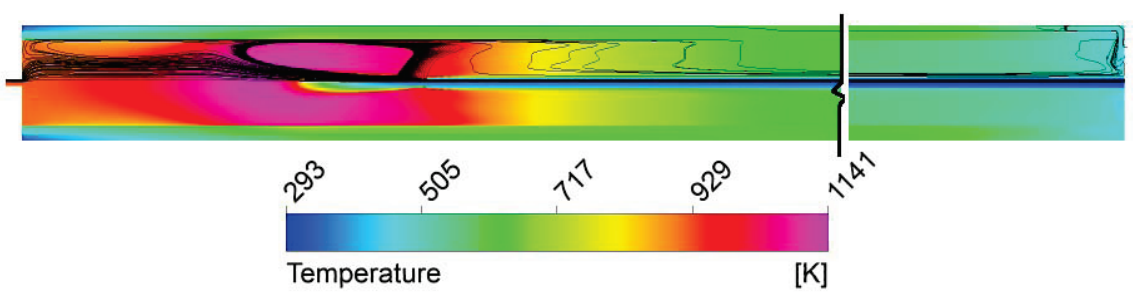

Figure 5: Contours of temperature given by the model. Pathlines are shown in half of the domain.

It also provides information about the reaction zone and the residence time distribution curves. According to figure 6, the fuel is completely burned at the flame, near the injector outlet. RTD analysis of this case indicates that the mean residence times of the flow leaving the reactor through the top and bottom outlets are $5.6 \mathrm{~s}$ and $76.8 \mathrm{~s}$, respectively. RTD curves are presented in figure 7. If the upper effluent fraction is reduced to $50 \%$, the same analysis predicts a residence time of $6.5 \mathrm{~s}$ for the top effluent and $45.3 \mathrm{~s}$ for the bottom effluent. This information is important when substances with slow oxidation kinetics are burned, where the residence time must be higher than the reaction time.

4.4. Influence of the IPA concentration

In order to analyze the influence of the IPA concentration in the temperatures profile along the reactor, experiments at injection temperature of $200{ }^{\circ} \mathrm{C}$ and at $85 \%$ upper effluent fraction condition were carried out in order to try to improve the removal of TOC at the bottom flow for the highest upper flow fractions. As it can be observed in the figure 8, higher IPA concentration generates higher temperatures in the top of the reactor. However, at the bottom of the reactor the temperatures are similar for both IPA concentrations when the upper effluent fraction remains constant. The values of TOC in both cases were lower than $10 \mathrm{ppm}$ at the top flow and lower than $100 \mathrm{ppm}$ at the bottom flow, but no improvements in the TOC bottom removal were observed. 


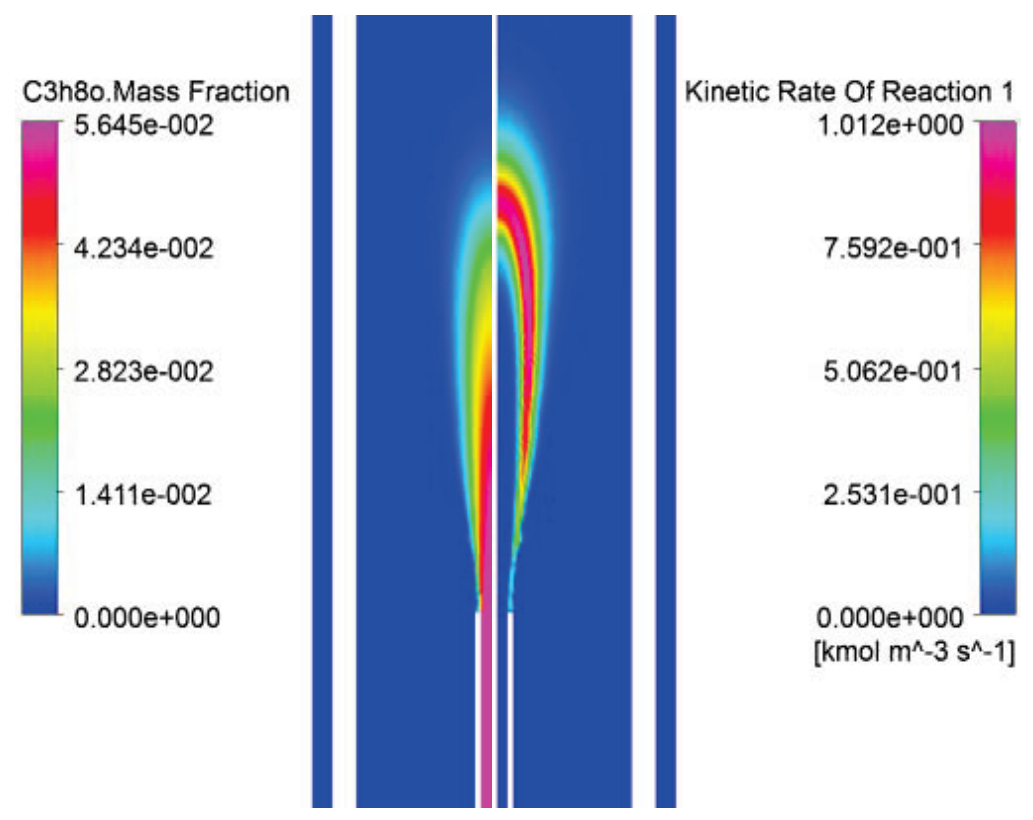

(a)

(b)

Figure 6: Simulation contours of new cooled wall reactor with two outlets: (a) IPA mass fraction, (b) reaction rate.

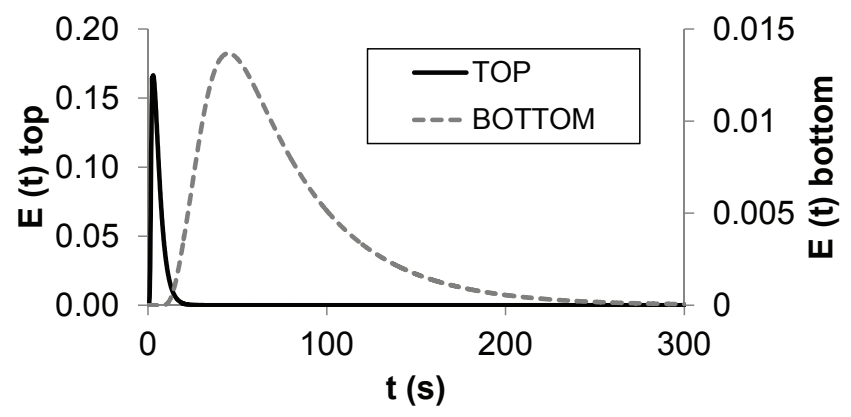

Figure 7: Residence time distribution curves for the new cooled wall reactor with two outlets. 


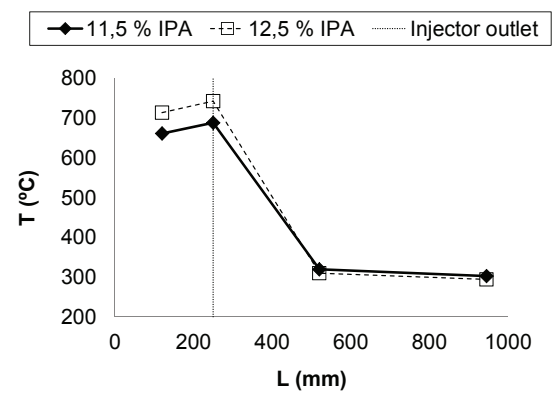

Figure 8: Temperature profile for different feed concentrations and with a relation of $85 \%$ of upper effluent fraction and an injection temperature of $200{ }^{\circ} \mathrm{C}$.

\subsection{Influence of the cooling water}

A study was performed trying to know the influence of the cooling water flow in the temperatures profiles along the reactor. The injection temperature of the experiment was $200{ }^{\circ} \mathrm{C}$ and the ratio top flow/total flow was fixed at $48 \%$. Three cooling water flows were studied: $5.2,6.8$ and $9.1 \mathrm{~kg} / \mathrm{h}$. (keeping the feed flow at $13.5 \mathrm{~kg} / \mathrm{h}$ ). The evolution of the temperature profiles along the reactor is shown in the figure $9 \mathrm{a}$. The figure shows that temperatures along

the whole reactor decrease when the cooling flow increases with a consequence reduction of the TOC removal in the bottom effluent as can be appreciated in figure $9 \mathrm{~b}$ where the values of TOC concentration are plotted as a function of the cooling flow. It is observed that from cooling flows higher than $9.1 \mathrm{~kg} / \mathrm{h}$ TOC concentration increases as much as $500 \mathrm{ppm}$ in the bottom effluent. With these results it can be noticed that a flow of $5-6 \mathrm{~kg} / \mathrm{h}$ of cooling water is enough to have good removals and keep the temperature at the bottom of the reactor below the supercritical temperature $\left(374^{\circ} \mathrm{C}\right)$, and that if a lower bottom temperature is required, an increase of the cooling flow could be worth but taking care with not decrease the TOC removal.

\subsection{Ammonia removal}

Different mixtures of IPA and ammonia were tested with the new configuration of the reactor. The main results obtained with this new configuration, 


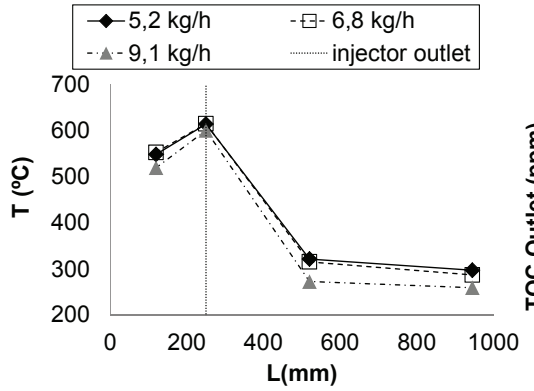

(a)

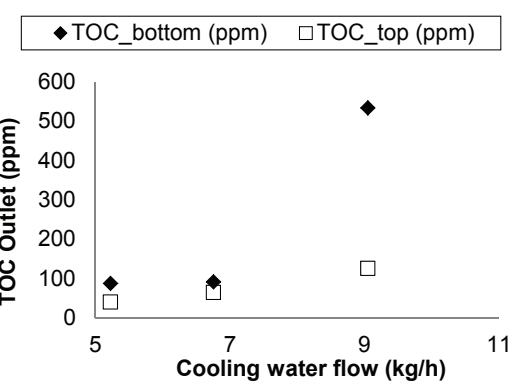

(b)

Figure 9: (a) Temperature profiles for different cooling water flows. (b) TOC values in top and bottom effluents for different cooling water flows.

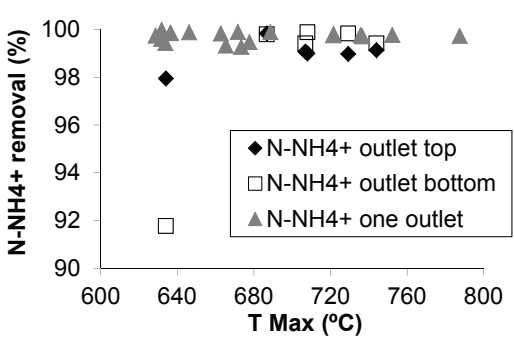

(a)

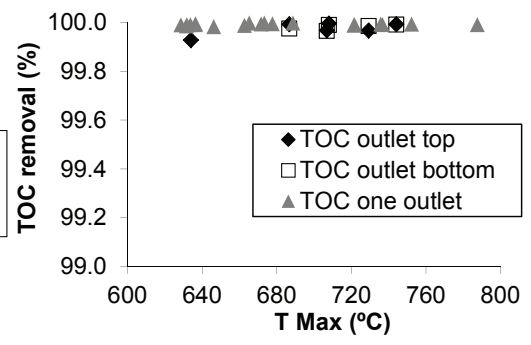

(b)

Figure 10: Ammonia removal (a) and TOC removal (b) vs max temperature inside the reactor for feeds with concentrations between $0.5-3 \%$ of ammonia and 9-11.5\% of IPA working with $100 \%$ bottom flow and with $50 \%$ top flow.

were compared with results obtained with mixtures of ammonia and IPA tested in the same reactor working with only the bottom outlet [4]. Figure 10 shows tered inside the reactor. The upper effluent fraction was kept constant at values around $50 \%$ which means that the $50 \%$ of the feed injected (liquid) has been taken out by the upper outlet. It can be appreciated that temperatures higher

$100 \%$ bottom flow and with $50 \%$ top flow.

than $700{ }^{\circ} \mathrm{C}$ are required to achieve $\mathrm{N}^{-N_{4}^{+}}$removals over $99 \%$. These temperatures are higher than those needed to obtain the same removal with the reactor working with only one outlet. Table 1 summarizes the average results for removal of the different experiments made with mixtures of ammonia and IPA. Working with two outlets, it is observed that ammonia removal is slightly 
Table 1: Removal results from the experiments made with different concentrations of ammonia.

\begin{tabular}{ccccccccc}
\hline $\begin{array}{c}\mathrm{NH}_{4}^{+} \mathrm{o} \\
(\%)\end{array}$ & $\begin{array}{c}\text { IPAo } \\
(\%)\end{array}$ & $\begin{array}{c}\mathrm{T}_{\max } \\
\left({ }^{\circ} \mathrm{C}\right)\end{array}$ & $\begin{array}{c}\text { TOC } \\
\text { Rem.(\%) } \\
\text { top }\end{array}$ & $\begin{array}{c}\text { TOC } \\
\text { Rem.(\%) } \\
\text { bottom }\end{array}$ & $\begin{array}{c}\mathrm{N}-\mathrm{NH}_{4}^{+} \\
\text {Rem.(\%) } \\
\text { top }\end{array}$ & $\begin{array}{c}\mathrm{N}-\mathrm{NH}_{4}^{+} \\
\text {Rem.(\%) } \\
\text { bottom }\end{array}$ & $\begin{array}{c}\mathrm{N}^{-\mathrm{NO}_{3}^{-}} \\
\text {top } \\
(\mathrm{ppm})\end{array}$ & $\begin{array}{c}\mathrm{N}-\mathrm{NO}_{3}^{-} \\
\text {bottom } \\
(\mathrm{ppm})\end{array}$ \\
\hline 0.5 & 11.5 & 744 & 99.99 & 99.99 & 99.13 & 99.41 & 49 & 38 \\
0.5 & 10.5 & 706 & 99.97 & 99.96 & 99.07 & 99.41 & 47 & 21 \\
0.5 & 10.0 & 634 & 99.93 & 94.71 & 97.94 & 91.77 & 50 & 14 \\
1.0 & 10.0 & 708 & 99.99 & 99.99 & 98.99 & 99.88 & 36 & 74 \\
3.0 & 9.0 & 686 & 99.99 & 99.97 & 99.83 & 99.79 & 186 & 78 \\
3.0 & 9.5 & 729 & 99.97 & 99.98 & 99.29 & 99.82 & 26 & 27 \\
\hline
\end{tabular}

higher in the bottom effluent than in the top effluent, probably because the residence time for the products comprising the lower effluent is longer than the one of the top effluent, that it seems to be too short to have complete oxidation of ammonia [4]. Nitrate concentration is in general higher in the top effluent due to the higher temperatures. The concentrations of $\mathrm{NOx}$ and $\mathrm{NH}_{4}^{+}$in the gas effluent were under the detection limit of 0.5 and 5 ppm respectively for all the experimental conditions tested.

\subsection{Behavior of the reactor working with high salt content feeds}

The main goal of this new design of the reactor is to obtain a top effluent at high temperature and free of salts, becoming this way available to be used in systems to produce energy. To achieve that, salts contained in the feed must precipitate and fall, leaving the reactor dissolved in the bottom effluent while the top effluent is free of salts. For this purpose, feeds with $\mathrm{Na}_{2} \mathrm{SO}_{4}$ concentrations until $2.5 \%(25,000 \mathrm{ppm})$ were injected in the reactor, using IPA as fuel to obtain reaction temperatures of $700{ }^{\circ} \mathrm{C}$, and at feed flow rates of $13-14$ $\mathrm{kg} / \mathrm{h}$. In table 2 the main results of the experiments made with feed containing salts are summarized. Equation (6) explains how the salt recovery is calculated. As can be observed in table 2, it is possible to recover a top effluent almost free of salts (with conductivities below values of the tap water, equivalent to concentrations of $\mathrm{Na}_{2} \mathrm{SO}_{4}$ lower than $30 \mathrm{ppm}$ ) and at temperatures over 500 ${ }^{\circ} \mathrm{C}$, available to be expanded in a turbine or for the production of steam at high 
Table 2: Main results for the experience made with feed containing 2.5\% wt of $\mathrm{Na}_{2} \mathrm{SO}_{4}$.

\begin{tabular}{cccccccc}
\hline $\begin{array}{c}\mathrm{F}_{\text {top }} \\
(\mathrm{kg} / \mathrm{h})\end{array}$ & $\begin{array}{c}\mathrm{F}_{\text {bottom }} \\
(\mathrm{kg} / \mathrm{h})\end{array}$ & $\begin{array}{c}\text { TOC } \\
\text { top } \\
(\mathrm{ppm})\end{array}$ & $\begin{array}{c}\text { TOC } \\
\text { bottom } \\
(\mathrm{ppm})\end{array}$ & $\begin{array}{c}\mathrm{T}_{\max } \\
\left({ }^{\circ} \mathrm{C}\right)\end{array}$ & $\begin{array}{c}\mathrm{T}_{\text {bottom }} \\
\left({ }^{\circ} \mathrm{C}\right)\end{array}$ & $\begin{array}{c}\mathrm{Na}_{2} \mathrm{SO}_{4} \\
\text { top } \\
(\mathrm{ppm})\end{array}$ & $\begin{array}{c}\mathrm{Na}_{2} \mathrm{SO}_{4} \\
\text { Recovery } \\
\text { bottom }(\%)\end{array}$ \\
\hline 7.2 & 10.2 & 1.0 & 209 & 749 & 239 & 24 & 2.4 \\
7.2 & 10.2 & 0.3 & 352 & 712 & 244 & 23 & 32.1 \\
7.2 & 10.2 & 0.5 & 599 & 740 & 250 & 24 & 21.1 \\
7.2 & 10.2 & 0.8 & 23 & 742 & 254 & 23 & 1.8 \\
7.2 & 10.2 & 0.7 & 69 & 683 & 258 & 23 & 45.5 \\
7.2 & 10.2 & 0.7 & 16 & 691 & 258 & 26 & 0.7 \\
\hline Average & & 0.7 & 211 & 719 & 251 & 23.8 & 17.3 \\
\hline
\end{tabular}

317 temperature that could be also expanded in a turbine. Paying attention to the 318 salt recovery at the bottom flow, it was possible to obtain an average of $17 \%$ of 319 salt recovery. This recovery is higher than the obtained with the reactor working with only one outlet [32] (average of 10\%) but it was not possible to improve 321 and stabilize the recovery during long times. This fact could be interpreted as 322 the possible formation of solid clusters of salts swept away by the outlet stream 323 and dissolved in the cooling systems.

\subsection{Energy recovery}

In order to analyze the possibility of using the high temperature of the effluent of SCWO reactors to produce energy, an analysis of the options for generating energy was performed.

\subsubsection{Parameter calculations}

The following equations explain how the different parameters for the study were calculated. Firstly, the amount of energy released by the waste and fuel contained in the feed is calculated as shown in eq. (7).

$$
\mathrm{kW} \text { injected at the feed }=\frac{F_{\text {feed }} C_{\text {fuel }} \Delta H_{\mathrm{c}, \text { fuel }}}{3,600}
$$

where $\Delta H_{\mathrm{c} \text {,fuel }}$ is the enthalpy of combustion for IPA $(3,750 \mathrm{~kJ} / \mathrm{kg})$.

The energy consumed is due mainly to the pumping equipment (pumps and 
compressors). The fraction of energy consumed with respect of the energy contained in the feed is calculated as shown in eq. (8).

$$
\text { Consumption }=\frac{\mathrm{kW} \text { Consumed }}{\mathrm{kW} \text { injected at the feed }} \cdot 100
$$

The energy production is calculated using Peng-Robinson Equation of State with Boston-Mathias alpha function considering a turbine with an isentropic efficiency of $72 \%$. The fraction of energy produced with respect to the energy introduced in the feed is calculated as shown in eq. (9).

$$
\text { Relative production }=\frac{\mathrm{kW} \text { produced }}{\mathrm{kW} \text { injected at the feed }} \cdot 100
$$

$\mathrm{kW}$ produced is the energy produced by direct expansion or steam expansion production.

From the production and consumption is obtained the percentage of the efficiency in energy production of the system of each reactor and kind of oxidant as shown in eq. (10).

$$
\text { Efficiency }=\frac{\mathrm{kW} \text { produced }-\mathrm{kW} \text { Consumed }}{\mathrm{kW} \text { injected at the feed }} \cdot 100
$$

Mass and energy balances were solved in Aspen Plus software considering thermal and volumetric properties calculated using Peng-Robinson Equation of State.

\subsubsection{Energy produced by steam expansion}

The most conventional method for electric generation is using the products stream as heat source for a Rankine cycle. As a guidance of feasibility of the process, it has been calculated the amount of steam which could be generated at different conditions for three small turbines commercialized by Siemens (table $3)$.

Increasing the pressure of the power cycle, increases the specific work produced by expanding the steam. However, the total amount of steam is reduced, since the heat source is limited. That can be seen in figure 11, that shows the composite curves for the hot stream (reactor products) and three possibilities of 
Table 3: Characteristics of commercial steam turbines.

\begin{tabular}{cccc}
\hline & $\begin{array}{c}\text { Inlet } \mathrm{P} \\
(\text { bar })\end{array}$ & $\begin{array}{c}\text { Inlet T } \\
\left({ }^{\circ} \mathrm{C}\right)\end{array}$ & $\begin{array}{c}\text { Power } \\
(\mathrm{kWh} /(\mathrm{kg} \text {-steam }))\end{array}$ \\
\hline SST-040 & 40 & 400 & 0.232 \\
SST-050 & 101 & 500 & 0.272 \\
SST-060 & 131 & 530 & 0.278 \\
\hline
\end{tabular}

342 cold stream (water-steam), with a difference of $10{ }^{\circ} \mathrm{C}$ at pinch point. The heat ${ }_{343}$ source is a stream at $700{ }^{\circ} \mathrm{C}$ and $23 \mathrm{MPa}$, with the typical composition of SCWO 344 effluent using air as oxidant. Finally, figure 12 presents the amount of steam 345 that could be produced per kilogram of hot products and the net efficiency for each pressure level.

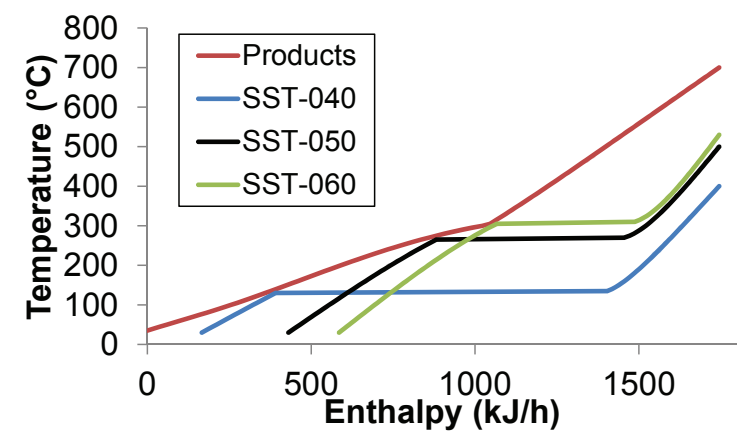

Figure 11: Production of steam at three different pressure levels.

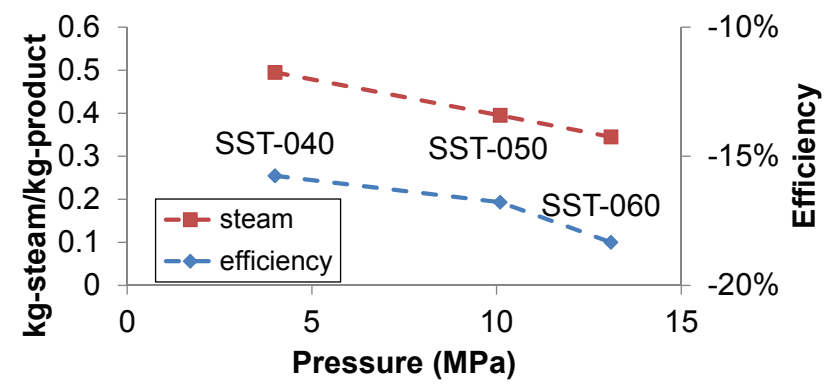

Figure 12: Steam production and efficiency for commercial turbines.

${ }_{347}$ Given these results, the following sections assume that the characteristics 
of the steam that can be produced from the heat contained in the effluent of the reactor are those shown in table 4 . The low pressure steam presented in

\begin{tabular}{lcc}
\multicolumn{3}{c}{ Table 4: Characteristics of the steam. } \\
\hline & $\begin{array}{c}\text { Pressure } \\
\text { (bar) }\end{array}$ & $\begin{array}{c}\text { Temperature } \\
\left({ }^{\circ} \mathrm{C}\right)\end{array}$ \\
\hline High Pressure Steam & 46 & 400 \\
Low Pressure Steam & 10 & 180 \\
\hline
\end{tabular}

349
Figure 13: System recovery design for a tubular reactor.

- Tubular reactor $[4,13]$

This reactor consisted on a straight and empty tube made of Ni alloy C-276 with a total length of $5400 \mathrm{~mm}$ and a diameter of $1 / 4$ " (i.d. 3.86 $\mathrm{mm}$ ) giving an internal volume of $63.2 \mathrm{ml}$ and it was thermally isolated. In this case (figure 13), the effluent is used firstly to preheat the feed until the injection temperature (around $400{ }^{\circ} \mathrm{C}$ ) and the remaining heat flow is used to produce steam.




- Original cooled wall reactor designed in the University of Valladolid (Valladolid, Spain) [33]

This reactor is composed by two concentric tubes; the inner one is made of Inconel 625, and the outer shell is made of SS 316. Oxidation reaction takes place inside the inner tube (reaction chamber). In the gap between both tubes, the pressurized feed stream is going down and cooling the reaction media at the same time. In such way, the inner tube does not withstand any pressure at all; having the same pressure in one side than on the other, and the thickness of the inner tube (Inconel 625) can be reduced. The effluent of the original CWR (at $400{ }^{\circ} \mathrm{C}$ ) can be used in a Rankine cycle as it is shown in figure 14 .

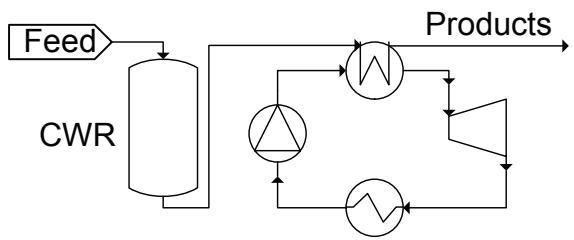

Figure 14: System recovery design for the original CWR.

- New cooled wall reactor design [32]

The new reactor consists of a vertical Ni-alloy reaction chamber that is inside of a pressure vessel made of AISI 316 able to stand a maximum pressure of $30 \mathrm{MPa}$ and $400{ }^{\circ} \mathrm{C}$. Between the walls of the two vessels a stream of cold water refrigerates the reaction vessel. The reagents (feed and oxidant) are introduced in the reactor through a tubular injector up to the top of the reaction chamber. The flame is produced outside of the injector, normally at the top of the reaction chamber, where the maximum temperature is registered. Reaction chamber is refrigerated with room temperature pressurized water that flowed between the reaction chamber wall and the inner wall which supported the pressure, keeping the pressurized wall at temperatures lower than $400{ }^{\circ} \mathrm{C}$, and entering in the reaction chamber by its lower part mixing with the reaction products. The prod- 
ucts flowed down the reactor leaving it by its lower part together with the cooling water. Following the idea of the original CWR, the products come

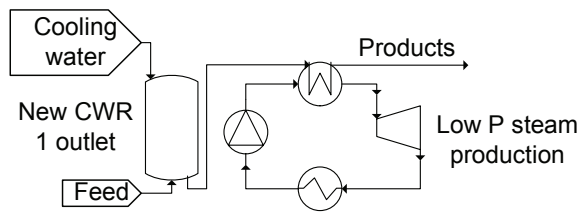

Figure 15: System recovery designed for the new CWR with the configuration with one outlet.

Figure 16: System recovery designed for the new CWR with the configuration with two outlets.

396

out the reactor at temperatures around $325^{\circ} \mathrm{C}$ and can produce steam to be expanded in a Rankine cycle (figure 15).

Other configuration of this reactor is working with an outlet at the top of the reactor, thus having two outlets: one at high temperature and other at subcritical temperatures with the salt dissolved with the cooling water (figure 16). For performing the comparative energetic analysis among the

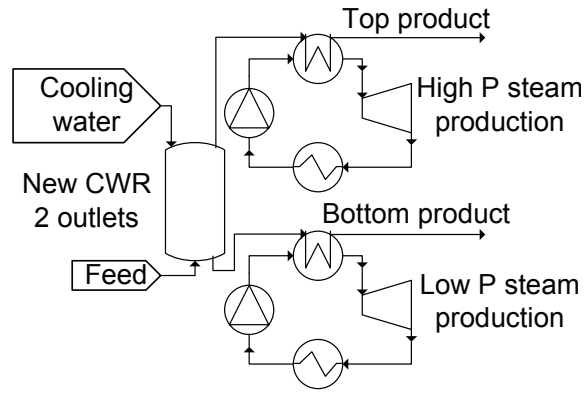

different reactors types, typical operational parameters for each reactor such as fuel concentration, oxidant excess over the stoichiometric amount (based on the average excess used in the majority of the experiments and the acceptable oxidant excess to oxidize nitrogen compounds), the percentage of cooling water and the effluent temperature were fixed. These parameters are shown in table 5. In first place, the analysis was performed considering that the effluents are used to generate steam for a Rankine cycle. The results are also shown in table 5, at the last two columns. 
As can be observed, producing electricity through Rankine cycles present

Table 5: Conditions fixed for the study of each reactor, recovering energy through a Rankine cycle. $5 \%$ excess of oxidant is assumed in all cases.

\begin{tabular}{|c|c|c|c|c|c|c|}
\hline \multirow{2}{*}{ Type of reactor } & \multirow{2}{*}{$\begin{array}{c}\text { Heat } \\
\text { flow feed } \\
(\mathrm{kW})\end{array}$} & \multirow{2}{*}{$\begin{array}{c}\text { Cooling } \\
\text { water } \\
\text { (\% of feed) }\end{array}$} & \multirow{2}{*}{$\begin{array}{l}\text { Injection } \\
\mathrm{T}\left({ }^{\circ} \mathrm{C}\right)\end{array}$} & \multirow{2}{*}{$\begin{array}{l}\text { Effluent } \\
\mathrm{T}\left({ }^{\circ} \mathrm{C}\right)\end{array}$} & \multicolumn{2}{|c|}{ Efficiency } \\
\hline & & & & & Air & $\mathrm{O}_{2}$ \\
\hline Original CWR & 1,202 & 0 & Room T & 400 & $-16.9 \%$ & $8.6 \%$ \\
\hline New CWR 1 outlet & 1,202 & 35 & Room $\mathrm{T}$ & 325 & $-16.8 \%$ & $4.8 \%$ \\
\hline Tubular reactor & 372 & 0 & $350-400$ & 700 & $-21.1 \%$ & $5.7 \%$ \\
\hline $\begin{array}{l}\text { New CWR } 2 \text { outlets } \\
100 \%\end{array}$ & 1,208 & 35 & Room $\mathrm{T}$ & $\begin{array}{l}\text { Top } 700 \\
\text { Bot. } 300\end{array}$ & $-8.0 \%$ & $19.0 \%$ \\
\hline $\begin{array}{l}\text { New CWR } 2 \text { outlets } \\
70 \%\end{array}$ & 1,208 & 35 & Room $\mathrm{T}$ & $\begin{array}{l}\text { Top } 700 \\
\text { Bot. } 300\end{array}$ & $-11.0 \%$ & $14.0 \%$ \\
\hline
\end{tabular}

only positive efficiencies (to be able to cover the energy consumption required by the pumping equipment) when the system is using oxygen as the oxidant. This is due to the much higher consumption of air compressors compared to liquid oxygen cryogenic pumps. Actually, the energy required (defined in equation (8)) when using air and oxygen ascends to $28 \%$ and $0.2 \%$, respectively.

\subsubsection{Energy recovery with the new cooled wall reactor}

Focusing on the new CWR reactor design, a detailed analysis of the energetic recovery possibilities is shown above. In figure 17 it is shown another possibility of energy recovery for each effluent of the new CWR design, besides scheme shown in figure 16. It was assumed, as observed experimentally, that all the gases involved in the combustion leaves the reactor with the top effluent: $\mathrm{CO}_{2}$ produced in the reaction, $\mathrm{N}_{2}$ (when air is used as oxidant) and $\mathrm{O}_{2}$ from the oxidant mixed with the water flow, being the bottom effluent considered as pure water.

\section{Influence of the distribution flow through different parameters}

To analyze the electricity production with the new CWR reactor, the conditions assumed are: $5 \%$ oxidant excess; $1,208 \mathrm{~kW}$ of heat flow feed; flow of cooling 


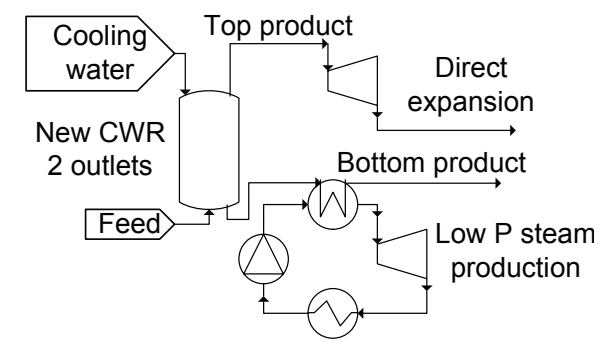

Figure 17: Scheme of the direct expansion of top effluent for the recovery energy with the CWR with 2 outlets.

${ }_{424}$ water equivalent to $35 \%$ of feed flow; and effluent temperatures of $700{ }^{\circ} \mathrm{C}$ and ${ }_{425} 300{ }^{\circ} \mathrm{C}$, at top and bottom outlets, respectively. The selected percentage of 426 cooling water is based on the optimal operational parameters obtained with the 427 new reactor.

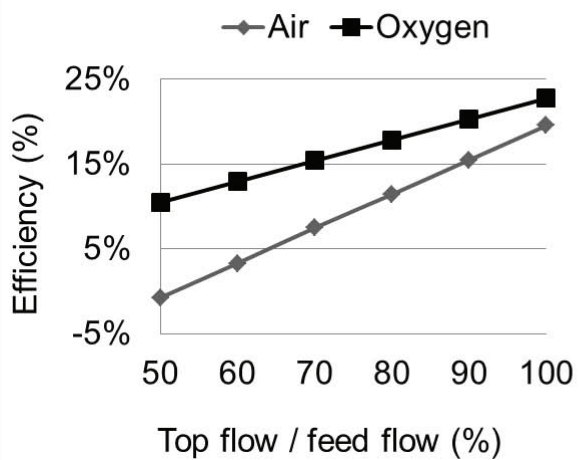

(a)

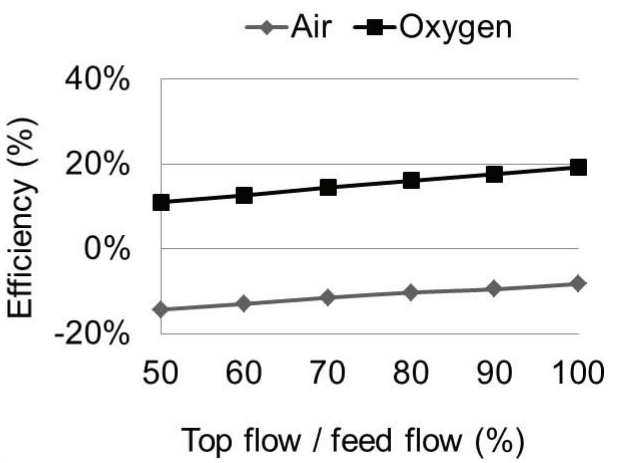

(b)

Figure 18: Efficiency of the recovery energy of the new reactor with (a) direct expansion and (b) steam production.

\section{Influence of the kind of energy production system}

Figure 18 shows the efficiency of the new reactor obtained by direct expansion of the flow and steam production working with air and with oxygen. Different flow

distributions are assumed. As can be observed, the energy produced by direct

expansion of the flow from the reactor is bigger than the energy obtained by the production of steam in a Rankine cycle that could be expanded afterwards. 
Also from figure 18 the effect of using air or oxygen can be seen. It is observed that when the top effluent is directly expanded in a turbine, working with air

${ }_{437}$ would be a possible option if flow distribution is over 55\% (top flow / feed flow). In the case of the expansion with the steam produced in the Rankine cycle, the consumption of the facility working with air as the oxidant is always higher than

${ }_{440}$ the energy produced. In both cases, oxygen offers better theoretical results with respect the energy production and energy pumping requirements.

\section{Conclusions}

We have presented a new cooled wall reactor design for supercritical water oxidation, capable of producing a high energy products stream with very low content of salts. Total elimination of organics and nitrogen compounds is achieved without needing of preheating the feed thanks to the hydrothermal

447 flame inside the reactor. Other important advantage of the new reactor is that

448 reaction and salt precipitation take place in one equipment.

Using IPA as fuel TOC removal was higher than $99.9 \%$ in both effluents while the percentage of products leaving the reactor in the top effluent was

451 lower than $70 \%$. Increasing top flow implies a reduction in elimination efficiency.

${ }_{452}$ Feed concentration affects the temperature of the system, but has no apparent influence over TOC elimination. The flow of cooling water must be the minimum necessary to keep a liquid (subcritical) level inside the reactor.

Removals of ammonia higher than $99 \%$ were possible with intermediate up456 per flow fractions and temperatures over $700{ }^{\circ} \mathrm{C}$ but the removal of ammonia in 457 the upper flow was lower than in the bottom flow probably due to the necessity

${ }_{458}$ of higher residence times for the oxidation of products coming out the reactor 459 trough the top outlet.

Experimental results using $\mathrm{Na}_{2} \mathrm{SO}_{4}$ as a model salt show that it is possible 461 to obtain a top effluent around $600{ }^{\circ} \mathrm{C}$, with a salt content lower than $30 \mathrm{ppm}$ 462 and a bottom effluent which allows recovering an average of $17 \%$ of salts at a 
temperature near $250{ }^{\circ} \mathrm{C}$.

Initial estimations about the energy recovery of the top flow indicates that the new reactor presents an improvement on energy recovery over other reactor designs, since the products are cleaner and hotter than the obtained in previous reactors. The process even can be self-sustained using oxygen and could be integrated in conventional plants for waste treatment.

Once that TOC and Ammonia elimination is guaranteed, the effects of operational parameters on energy integration will be studied. Further work is also necessary in designing real turbo-machines capable of expanding such products.

\section{Acknowledgments}

Authors thank Spanish Ministry of Economy and Competitiveness MINECO projects CTQ2011-23293, ENE2012-33613 and CTQ2013-44143-R for financial support. M.D. Bermejo thanks the Spanish Ministry of Economy and Competitiveness for the Ramn y Cajal research fellowship RYC-2013-13976. P. Cabeza thanks Junta de Castilla y León for predoctoral grant. J.P.S. Queiroz thanks the Spanish Education Ministry for the predoctoral grant FPU AP2009-0399. C. Jiménez thanks the Spanish Economy and Competitiveness Ministry for her predoctoral grant BES-2011-046496.

\section{References}

[1] W. Schilling, E. Franck, Combustion and Diffusion Flames at HighPressures to 2000 bar, Berichte Der Bunsen-Gesellschaft-Physical Chemistry Chemical Physics 92 (1988) 631-636.

[2] G. M. Pohsner, E. U. Franck, Spectra and temperatures of diffusion flames at high pressures to 1000 bar, Berichte der Bunsengesellschaft für physikalische Chemie 98 (1994) 1082-1090.

[3] C. Augustine, J. Tester, Hydrothermal flames: From phenomenological experimental demonstrations to quantitative understanding, Journal of Supercritical Fluids 47 (2009) 415-430. 
[4] P. Cabeza, M. D. Bermejo, C. Jimenez, M. J. Cocero, Experimental study of the supercritical water oxidation of recalcitrant compounds under hydrothermal flames using tubular reactors, Water Research 45 (2011) 24852495.

[5] R. M. Serikawa, T. Usui, T. Nishimura, H. Sato, S. Hamada, H. Sekino, Hydrothermal flames in supercritical water oxidation: investigation in a pilot scale continuous reactor, Fuel 81 (2002) 1147-1159.

[6] M. D. Bermejo, E. Fdez-Polanco, M. J. Cocero, Experimental study of the operational parameters of a transpiring wall reactor for supercritical water oxidation, Journal of Supercritical Fluids 39 (2006) 70-79.

[7] C. Oh, R. Kochan, T. Charlton, A. Bourhis, Thermal-hydraulic modeling of supercritical water oxidation of ethanol, Energy \& Fuels 10 (1996) 326332.

[8] B. Wellig, K. Lieball, P. von Rohr, Operating characteristics of a transpiring-wall SCWO reactor with a hydrothermal flame as internal heat source, Journal of Supercritical Fluids 34 (2005) 35-50.

[9] B. Wellig, M. Weber, K. Lieball, K. Prikopsky, P. von Rohr, Hydrothermal methanol diffusion flame as internal heat source in a SCWO reactor, Journal of Supercritical Fluids 49 (2009) 59-70.

[10] K. Príkopský, B. Wellig, P. R. von Rohr, SCWO of salt containing artificial wastewater using a transpiring-wall reactor: Experimental results, The Journal of Supercritical Fluids 40 (2007) 246-257.

[11] M. D. Bermejo, F. Fdez-Polanco, M. J. Cocero, Effect of the transpiring wall on the behavior of a supercritical water oxidation reactor: Modeling and experimental results, Industrial \& Engineering Chemistry Research 45 (2006) 3438-3446.

[12] F. Zhang, C. Xu, Y. Zhang, S. Chen, G. Chen, C. Ma, Experimental study on the operating characteristics of an inner preheating transpiring 
wall reactor for supercritical water oxidation: Temperature profiles and product properties, Energy 66 (2014) 577-587.

[13] M. D. Bermejo, P. Cabeza, M. Bahr, R. Fernandez, V. Rios, C. Jimenez, M. J. Cocero, Experimental study of hydrothermal flames initiation using different static mixer configurations, Journal of Supercritical Fluids 50 (2009) 240-249.

[14] M. D. Bermejo, P. Cabeza, J. P. S. Queiroz, C. Jimenez, M. J. Cocero, Analysis of the scale up of a transpiring wall reactor with a hydrothermal flame as a heat source for the supercritical water oxidation, Journal of Supercritical Fluids 56 (2011) 21-32.

[15] P. Cabeza, J. P. S. Queiroz, S. Arca, C. Jiménez, A. Gutiérrez, M. D. Bermejo, M. J. Cocero, Sludge destruction by means of a hydrothermal flame. Optimization of ammonia destruction conditions, Chemical Engineering Journal 232 (2013) 1-9.

[16] J. P. S. Queiroz, M. D. Bermejo, F. Mato, M. J. Cocero, Supercritical water oxidation with hydrothermal flame as internal heat source: Efficient and clean energy production from waste, The Journal of Supercritical Fluids 96 (2015) 103-113.

[17] E. Facchinetti, M. Gassner, M. D'Amelio, F. Marechal, D. Favrat, Process integration and optimization of a solid oxide fuel cell - Gas turbine hybrid cycle fueled with hydrothermally gasified waste biomass, Energy 41 (2012) 408-419.

[18] I. Rönnlund, L. Myréen, K. Lundqvist, J. Ahlbeck, T. Westerlund, Waste to energy by industrially integrated supercritical water gasification - Effects of alkali salts in residual by-products from the pulp and paper industry, Energy 36 (2011) 2151-2163.

[19] M. D. Bermejo, M. J. Cocero, F. Fernandez-Polanco, A process for gen- 
erating power from the oxidation of coal in supercritical water, Fuel 83 (2004) 195-204.

[20] F. Donatini, G. Gigliucci, J. Riccardi, M. Schiavetti, R. Gabbrielli, S. Briola, Supercritical water oxidation of coal in power plants with low CO2 emissions, Energy 34 (2009) 2144-2150.

[21] J. Kotowicz, S. Michalski, Efficiency analysis of a hard-coal-fired supercritical power plant with a four-end high-temperature membrane for air separation, Energy 64 (2014) 109-119.

[22] K. Arai, R. L. Smith Jr., T. M. Aida, Decentralized chemical processes with supercritical fluid technology for sustainable society, The Journal of Supercritical Fluids 47 (2009) 628-636.

[23] M. J. Cocero, E. Alonso, M. T. Sanz, F. Fdz-Polanco, Supercritical water oxidation process under energetically self-sufficient operation, The Journal of Supercritical Fluids 24 (2002) 37-46.

[24] E. D. Lavric, H. Weyten, J. De Ruyck, V. Pleşu, V. Lavric, Supercritical water oxidation improvements through chemical reactors energy integration, Applied Thermal Engineering 26 (2006) 1385-1392.

[25] R. L. Smith Jr., T. Adschiri, K. Arai, Energy integration of methane's partial-oxidation in supercritical water and exergy analysis, Applied Energy 71 (2002) 205-214.

[26] A. A. Peterson, F. Vogel, R. P. Lachance, M. Fröling, J. Michael J. Antal, J. W. Tester, Thermochemical biofuel production in hydrothermal media: A review of sub- and supercritical water technologies, Energy \& Environmental Science 1 (2008) 32-65.

[27] M. Gassner, F. Vogel, G. Heyen, F. Maréchal, Optimal process design for the polygeneration of SNG, power and heat by hydrothermal gasification of waste biomass: Thermo-economic process modelling and integration, Energy \& Environmental Science 4 (2011) 1726-1741. 
[28] ANSYS, ANSYS FLUENT Theory Guide Release 12, 2009.

[29] A. Peneloux, E. Rauzy, R. Freze, A consistent correction for RedlichKwong-Soave volumes, Fluid Phase Equilibria 8 (1982) 7-23.

[30] D.-Y. Peng, D. B. Robinson, A New Two-Constant Equation of State, Industrial \& Engineering Chemistry Fundamentals 15 (1976) 59-64.

[31] G. P. Mathur, G. Thodos, The self-diffusivity of substances in the gaseous and liquid states, AIChE Journal 11 (1965) 613-616.

[32] M. D. Bermejo, C. Jimenez, P. Cabeza, A. Matias-Gago, M. J. Cocero, Experimental study of hydrothermal flames formation using a tubular injector in a refrigerated reaction chamber. Influence of the operational and geometrical parameters, Journal of Supercritical Fluids 59 (2011) 140-148.

[33] M. J. Cocero, D. Vallelado, R. Torio, E. Alonso, F. Fdez-Polanco, Optimisation of the operation variables of a supercritical water oxidation process, Water Science and Technology 42 (2000) 107-113. 